\title{
Winterschutz für empfindliche Gewächse im Winter 2019/2020
}

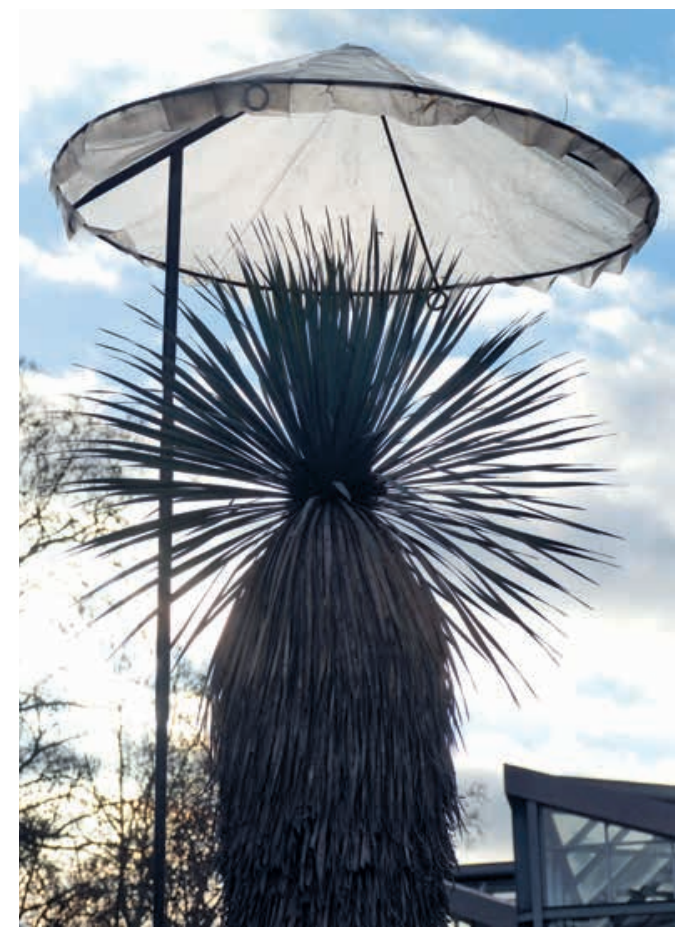

Abb. 1: Die winterharten Yuccas im Sommer-Sukkulentengarten bekommen eine Haube. (Foto: H. STEINEcke)

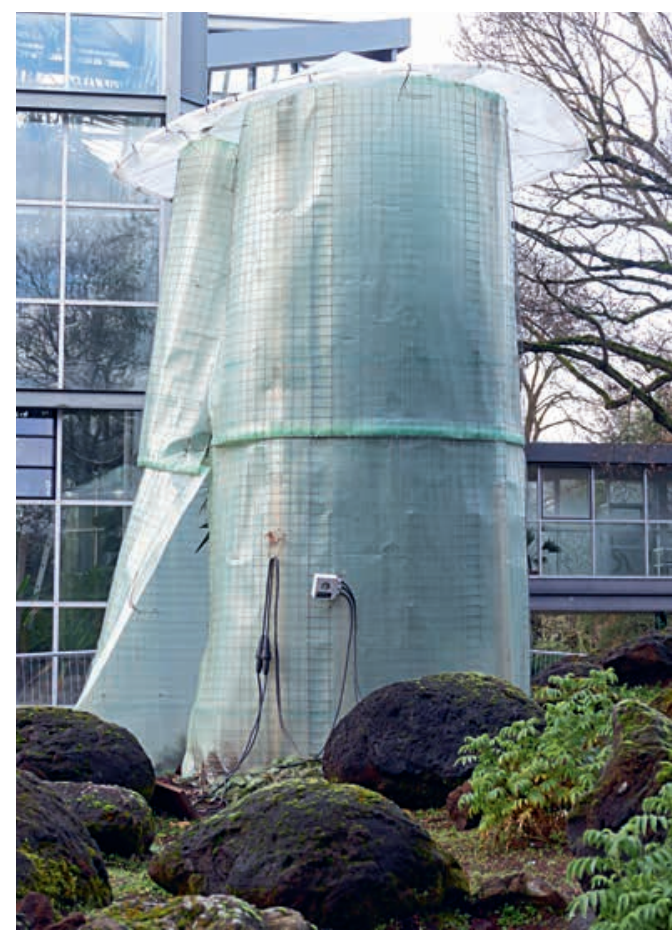

Abb. 2: Die ChilenischeZuckerpalme ist komplett eingehaust. (Foto: H. STEINecke)

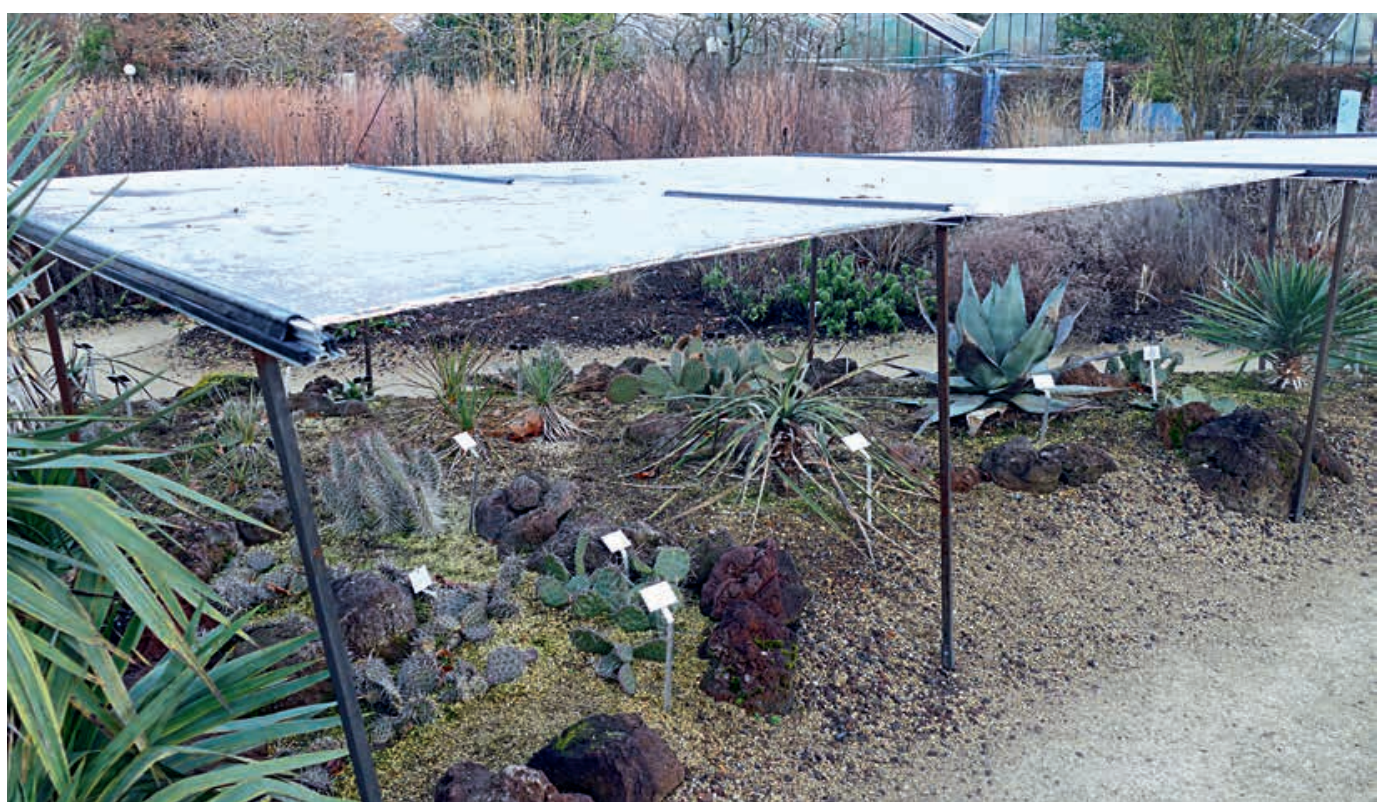

Abb. 3: Ein Dach schützt in der Steppenanlage winterharte Kakteen und Agaven vor zu viel Feuchtigkeit. (Foto: H. STEINEcke) 


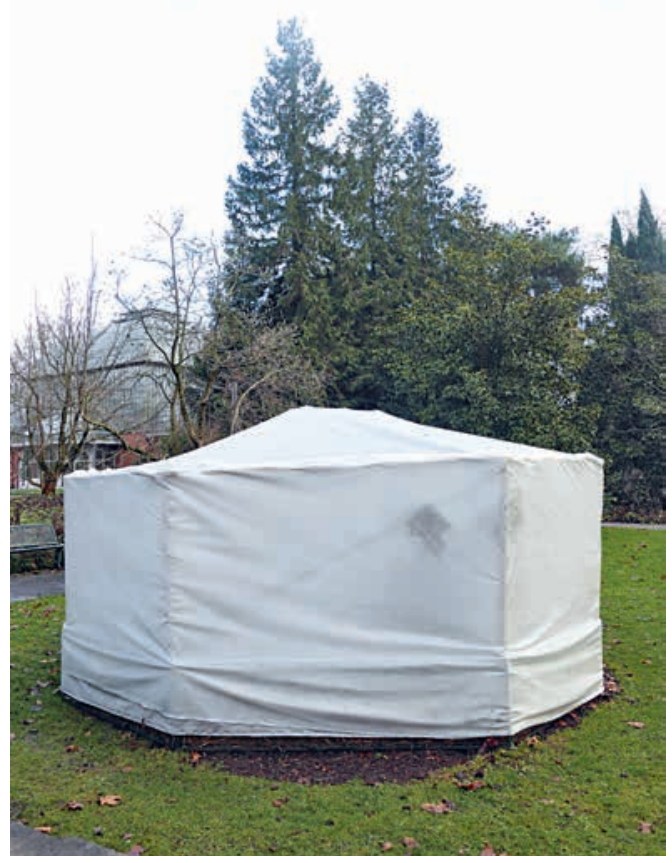

Abb. 4: Wie ein Partyzelt wirkt der Winterschutz für die Chinesische Faserbanane. (Foto: H. STEInecke)

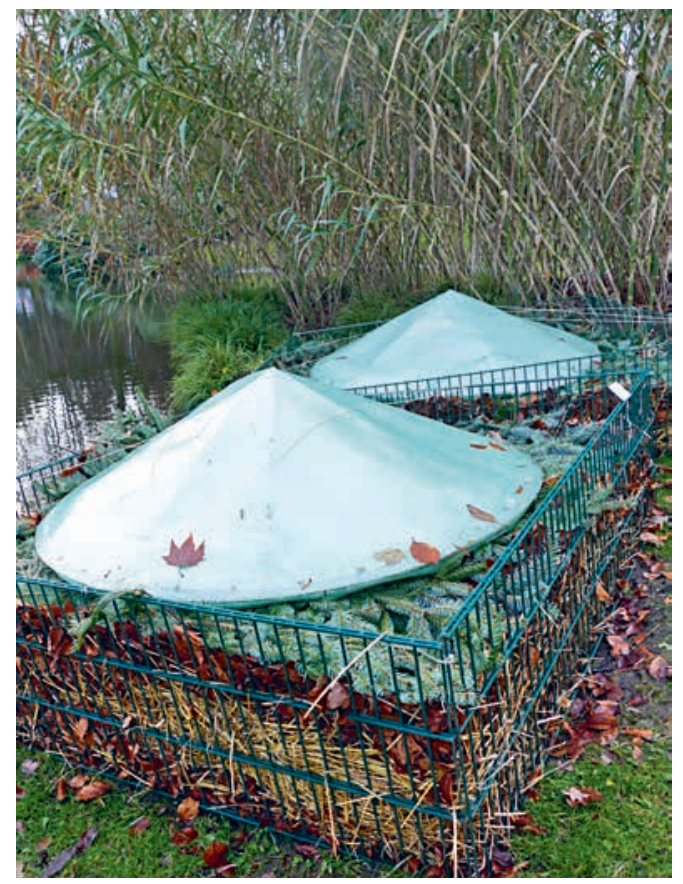

Abb. 5: Stroh, Laub und „Hüte“ schützen die GunneraPflanzen am kleinen Weiher. (Foto: H. Steinecke)

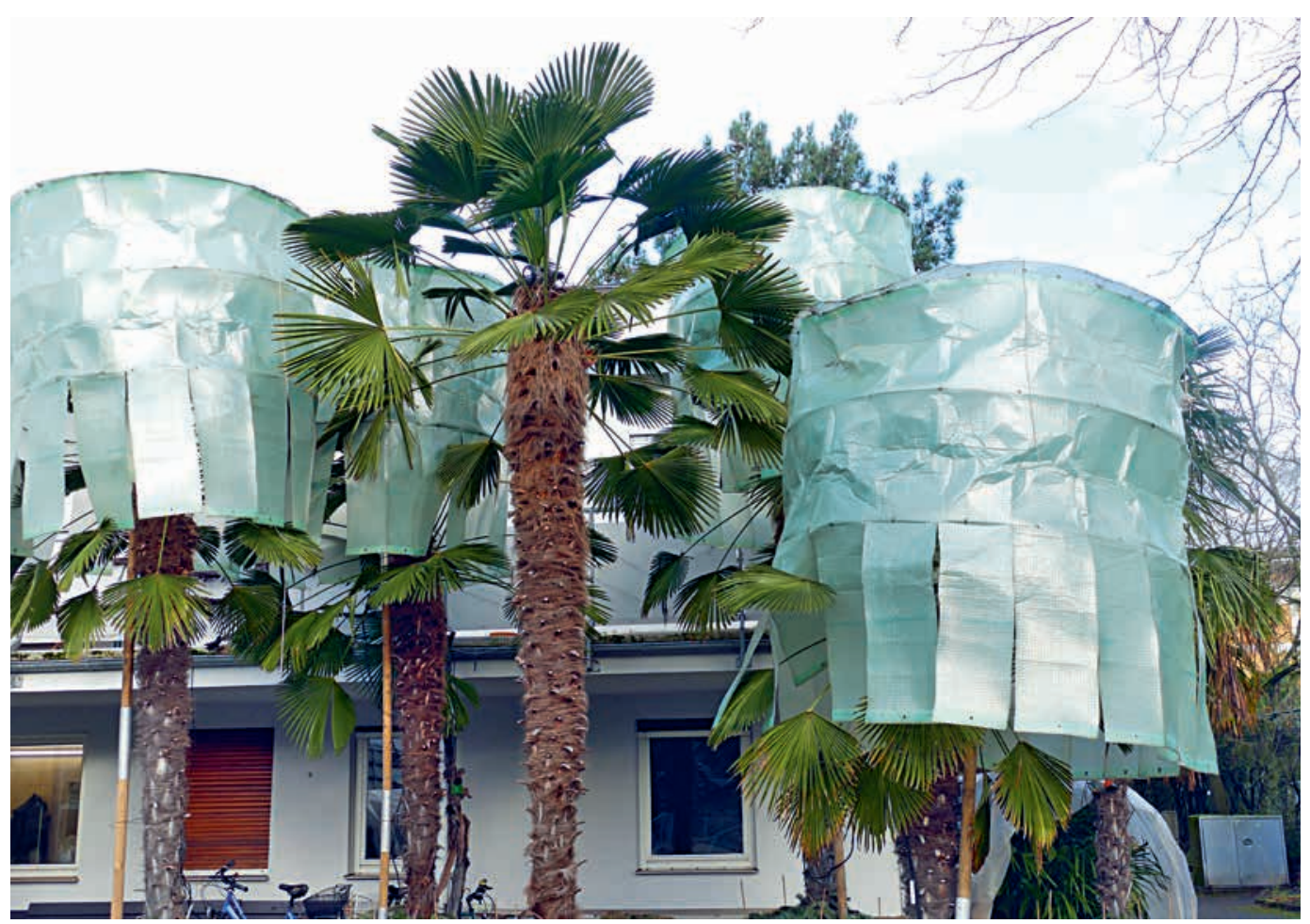

Abb. 6: Die verhüllten Hanfpalmen am Sukkulentengarten erinnern an große Stehlampen. (Foto. H. Steinecke) 